\title{
On Categories, Pictures, and the Goals of Comparative Psychology
}

\author{
Olga F. Lazareva \\ Drake University
}

Keywords: Categorization, pigeons, visual discrimination, photographs

The ability to categorize objects and events has long been an object of an intense interest and rigorous research in both humans and nonhuman animals (see Lazareva \& Wasserman, 2008; Mareschal, Quinn, \& Lea, 2010, for reviews). Until the seminal Herrnstein and Loveland's study (1964), most of the comparative research used simple and well-defined stimuli (e.g., $1000-\mathrm{Hz}$ tone or a $450 \mathrm{~nm}$ light) as discriminanda. Although easily controllable, such stimuli have little relationship to the tasks faced by animals in their natural environments: After all, discriminating a hawk from a conspecific is unlikely to be based on the difference in a single wavelength or pure tone.

Using more realistic stimuli, Herrnstein and Loveland (1964) demonstrated that pigeons can learn to discriminate color photographs that contain people from photographs that do not contain people, despite considerable variability in these photographs. Even more remarkably, the task did not appear to be difficult for pigeons. Herrnstein and Loveland reported that pigeons "showed some grasp of the concept" (p. 550) within 560 to 800 trials with 80 unique photographs; in other words, these pigeons have only seen each individual photograph 10 times or less. For comparison, successful discrimination of line drawings of circle and square in a go/ no-go procedure can require 473 trials on average, ranging from 280 to 660 trials (Towe, 1954). Similar results were reported by others, suggesting that despite the enormous Correspondence concerning this article should be addressed to Olga Lazareva, Department of Psychology, Drake University, Des Moines, IA 50311. Email: olga.lazareva@drake.edu variability in pictorial content, categorization with pictures of natural objects is at least as easy, if not easier, than categorization of "simpler", artificially constructed objects (e.g., Cerella, 1977; Cerella, 1979).

Of course, introduction of the complexity of photographs into comparative research came at a price. Firstly, just what is the feature (or features) controlling the discrimination? Many studies have attempted to answer this question with different degree of success, since photographs of natural objects have many potential discriminative properties that are difficult to pinpoint and control (see Lazareva \& Wasserman, 2008, for a review). Secondly, do animals view target objects on the photographs as representations of the real objects in the world? This second question has concerned many researchers (e.g., Fagot, 2000), and it is at the center of Weisman and Spetch' (2010) review.

Weisman and Spetch (2010) posit that picture-object correspondence must be established first in order to interpret categorization research. They further assert that using human-language labels for categories (e.g., cars) constitutes anthropomorphism unless there is an evidence supporting correspondence between the pictures of the members of categories and three-dimensional objects in real world. Finally, they claim that the goal of comparative psychology is to interpret how animals view the natural world and behave in it, and that this goal can only be accomplished if the stimuli used in the lab correspond, in animals' view, to real-world objects. 
Do all stimuli used in categorization research need to have real-world counterparts in order to inform us about mechanisms of categorization? If the answer is "yes", then we must dismiss the many reports within the realm of human categorization that have used simple dimensional features, as rectangles of varying heights (Denton, Kruschke, \& Erikson, 2008), dots in various spatial locations (Maddox, Love, Glass, \& Filoteo, 2008), or Gabor patches (Sperling \& Ashby, 2008) as discriminative stimuli. Of course, such stimuli are used because they are easy to control and manipulate, and these highly analytic experiments have provided us with important insights into how human categorization works despite the tenuous relationship to real-world objects and tasks. The same holds true for research in comparative psychology.

Why would one use photographs of real-world objects instead of artificially constructed objects in comparative research, if the goal is to reveal basic mechanisms of categorization instead of establishing picture-object correspondence? There is a good practical reason: Despite many attempts, we still cannot construct artificial categories that successfully mimic properties of real-world categories and are easily learned by pigeons (see Lea, Wills, \& Ryan, 2006, for an extensive discussion of the problem). Consequently, photographs of real-world objects provide excellent stimulus material precisely because of the ease with which they are categorized by pigeons.

Moreover, the absence of picture-object correspondence may be an advantage for some of the research questions, instead of a drawback. Dissociation of living and non-living categories is a good example of such a question. Certain cerebral pathologies in humans have been found to produce impaired recognition and naming of living objects (e.g., animals, fruits, or vegetables), while leaving recognition of non-living objects (e.g., tools or furniture) intact, and vice versa (see Farah, 2004; Martin \& Caramazza, 2003, for reviews). One explanation of this dissociation states that categorization of non-living objects is based on their functional specifications or on the kinesthetic representation of the movements involved in using them, whereas the categorization of living objects is based on their perceptual properties (Damasio, 1990; Warrington \& McCarthy, 1987). Another explanation suggests that the difference is one of degree and not of kind: The members of living categories may be more perceptually similar to each other than are the members of non-living categories, and the difference in similarity may account for this dissociation (Gaffan \& Heywood, 1993; Humphreys, Riddoch, \& Quinlan, 1988; McRae \& Cree, 2002).

Since we cannot (and do not) assume that pigeons see pictures of cars as representations of real-world cars, they present an ideal model animal to distinguish among these two explanations. Any dissociation found between images of non-living objects (cars and chairs, in our case) and images of living objects (flowers and persons) ought to be ascribed to a difference in perceptual similarity rather than a difference in type of representation. In several experiments, we reported evidence consistent with greater perceptual similarity among natural categories than among artificial categories (Lazareva, Soto, \& Wasserman, in press; Lazareva, Freiburger, \& Wasserman, 2004; Lazareva, Freiburger, \& Wasserman, 2006; Lazareva \& Wasserman, 2009), suggesting that perceptual similarity alone may be sufficient for explaining living versus non-living dissociation in categorization tasks.

We disagree that our use of the terms "living" and "nonliving" in this context constitute a form of anthropomorphism. Researchers employing the terms "living" and "non-living" for the groups of images presented to a computer program do not imply that the computer program will be able to establish correspondence between these images and their real-world counterparts (Gale, Laws, Frank, \& Leeson, 2003); they merely use these terms as convenient labels for two groups of images. We do the same in our research with pigeons, simply because it would be rather awkward to refer to a group of eight photographs of cars as a Category A.

In recent years, research on basic mechanisms of learning, categorization, and vision appears to have fallen out of fashion. The search for basic mechanisms is dismissed as part of an "anthropocentric program" (Shettleworth, 1993), as opposed to "ecological" approach that concentrates on behaviors and stimuli that are relevant to animals' natural environments. Although Weisman and colleagues (Sturdy, Bloomfield, Farrell, Avey, \& Weisman, 2007; Weisman \& Spetch, 2010) do not use the term "anthropocentric program", they do argue that research devoted to general understanding of mechanisms of vision and attention is of little importance to our understanding of how animals perceive objects in their natural environments.

While I agree that the goal of comparative psychology is "to explain nature" (Weisman \& Spetch, 2010, line 581582 ), it seems to me that an understanding of the general mechanisms of learning and vision is part and parcel of a quest for such explanation, as much as understanding of animal behavior in its natural environment. It is now widely known now that ultraviolet vision contributes to mate choice in many birds. Would anyone, however, attempted to look at avian plumage under UV filter without prior experiments using highly simplified stimuli in laboratory environments demonstrating that birds' vision extends into ultraviolet portion of the spectrum (e.g., Bowmaker, 1977; Remy \& 
Emmerton, 1989)? In fact, the very first article on the effect of ultraviolet perception on mate choice (Bennett, Cuthill, Partridge, \& Maier, 1996) cites the results of basic vision research by J. K. Bowmaker (Bowmaker, Heath, Wilkie, \& Hunt, 1997) as an inspiration. I believe strongly that neither the "ecological" approach nor the "anthropocentric" approach is superior; both research programs can and should coexist and inform each other in order to ensure the progress of comparative psychology toward an understanding of the functions and mechanisms of animal cognition.

\section{References}

Bennett, A. T. D., Cuthill, I. C., Partridge, J. C., \& Maier, E. C. (1996). Ultraviolet vision and mate choice in zebra finches. Nature, 380, 433-435. doi:10.1038/380433a0

Bowmaker, J. K. (1977). The visual pigments, oil droplets and spectral sensitivity of the pigeon. Vision Research, 17, 1129-1138. doi: 10.1016/0042-6989(77)90147-X

Bowmaker, J. K., Heath, L. A., Wilkie, S. E., \& Hunt, D. M. (1997). Visual pigments and oil droplets from six classes of photoreceptor in the retinas of birds. Vision Research, 37, 2183-2194. doi:10.1016/S0042-6989(97)00026-6

Cerella, J. (1977). Absence of perspective processing in the pigeon. Pattern Recognition, 9, 65-68. doi:10.1016/00313203(77)90016-4

Cerella, J. (1979). Visual classes and natural categories in the pigeon. Journal of Experimental Psychology: Human Perception and Performance, 5, 68-77. doi:10.1037/0096$\underline{1523.5 .1 .68}$

Damasio, A. R. (1990). Category-related recognition defects as a clue to the neural substrates of knowledge. Trends in Neurosciences, 13, 95-98. doi:10.1016/01662236(90)90184-C

Denton, S. E., Kruschke, J. K., \& Erikson, M. A. (2008). Rule-based extrapolation: A continuing challenge for exemplar models. Psychonomic Bulletin and Review, 15, 780-786. doi: 10.3758/PBR.15.4.780

Fagot, J. (2000). Picture perception in animals. Philadelphia, PA: Psychology Press Ltd.

Farah, M. J. (2004). Visual Agnosia. 2nd ed. Cambridge, MA: The MIT Press.

Gaffan, D. \& Heywood, C. A. (1993). A spurious categoryspecific visual agnosia for living things in normal human and nonhuman primates. Journal of Cognitive Neuroscience, 5, 118-128. doi:10.1162/jocn.1993.5.1.118

Gale, T. M., Laws, K. R., Frank, R. J., \& Leeson, V. C. (2003). Basic-level visual similarity and category specificity. Brain and Cognition, 53, 229-231. doi:10.1016/S02782626(03)00115-5

Herrnstein, R. J. \& Loveland, D. H. (1964). Complex visual concept in the pigeon. Science, 146, 549-551. doi:10.1126/ science.146.3643.549 PMid:14190250

Humphreys, G. W., Riddoch, M. J., \& Quinlan, P. T. (1988). Cascade processes in picture identification. Cognitive Neuropsychology, 5, 67-103. doi: $10.1080 / 02643298808252927$

Lazareva, O. F., Freiburger, K. L., \& Wasserman, E. A. (2004). Pigeons concurrently categorize photographs at both basic and superordinate levels. Psychonomic Bulletin and Review, 11, 1111-1117. PMid:15875984

Lazareva, O. F., Freiburger, K. L., \& Wasserman, E. A. (2006). Effects of stimulus manipulations on visual categorization in pigeons. Behavioural Processes, 72, 224 233. doi:10.1016/j.beproc.2006.03.004 PMid:16616817

Lazareva, O. F., Soto, F. A., \& Wasserman, E. A. (in press). Effect of between-category similarity on basiclevel superiority in pigeons. Behavioural Processes. doi:10.1016/j.beproc.2010.06.014

Lazareva, O. F. \& Wasserman, E. A. (2008). Categories and concepts in animals. In R.Menzel (Ed.), Learning theory and behavior. Vol. 1 of Learning and memory: A comprehensive reference (edited by J. Byrne) (pp. 197226). Oxford: Elsevier.

Lazareva, O. F. \& Wasserman, E. A. (2009). Effects of stimulus duration and choice delay on visual categorization in pigeons. Learning and Motivation, 40, 132-146. doi:10.1016/j.lmot.2008.10.003 PMid:20161256 PMCid:2699671

Lea, S. E. G., Wills, A. J., \& Ryan, C. M. (2006). Why are artificial polymorphous concepts so hard for birds to learn? Quarterly Journal of Experimental Psychology, 59, 251267. doi:10.1080/02724990544000031 PMid:16618633

Maddox, T., Love, B. C., Glass, B. D., \& Filoteo, J. V. (2008). When more is less: Feedback effects in perceptual category learning. Cognition, 108, 578-589. doi: 10.1016/j. cognition.2008.03.010 PMid:18455155 PMCid:2467509

Mareschal,D., Quinn, P.C., \& Lea, S. E. G. (2010). The making of human concepts. New York, NY: Oxford University Press. doi: 10.1093/acprof:oso/9780199549221.001.0001 Martin, A. \& Caramazza, A. (2003). Neuropsychological and neuroimaging perspectives on conceptual knowledge: An introduction. Cognitive Neuropsychology, 20, 195212. doi:10.1080/02643290342000050

McRae, K. \& Cree, G. S. (2002). Factors underlying category-specific semantic deficits. In E.M.E.Forde \& G. W. Humphreys (Eds.), Category specificity in brain and mind (pp. 211-249). New York: Psychology Press, Taylor \& Francis Group.

Remy, M. \& Emmerton, J. (1989). Behavioral spectral sensitivities of different retinal areas in pigeons. Behavioral Neuroscience, 103, 170-177. doi: 10.1037/07357044.103.1.170 PMid:2923670

Shettleworth, S. J. (1993). Where is the comparison in comparative cognition? Alternative research 
programs. Psychological Science, 4, 179-184. doi:10.1111/j.1467-9280.1993.tb00484.x

Sperling, B. J. \& Ashby, F. G. (2008). Initial training with difficult items facilitates information integration, but not rule-based category learning. Psychological Science, 19, 1169-1177. doi: 10.1111/j.1467-9280.2008.02219.x PMid:19076490 PMCid:2605282

Sturdy, C. B., Bloomfield, L. L., Farrell, T. M., Avey, M. T., \& Weisman, R. G. (2007). Auditory category perception as a natural cognitive activity in songbirds. Comparative Cognition and Behavior Reviews, 2, 93-110. Retrieved from http://psyc.queensu.ca/ccbr/index.html doi: $\underline{10.3819 /}$ ccbr.2008.20006

Towe, A. L. (1954). A study of figural equivalence in the pigeon. Journal of Comparative and Physiological Psychology, 47, 283-287. doi: 10.1037/h0056584 PMid:13192219

Warrington, E. K. \& McCarthy, R. A. (1987). Categories and knowledge: Further fractionations and an attempted integration. Brain, 110, 1273-1296. doi: 10.1093/ brain/110.5.1273 PMid:3676701

Weisman, R., Spetch, M. (2010) Determining when birds perceive correspondence between pictures and objects: a critique. Comparative, Cognition and Behavior Reviews, 5, 117-131. Retrieved from http://psyc.queensu.ca/ccbr/

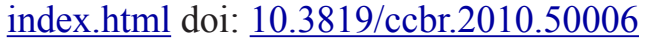

